\title{
A possible approach towards spin-polarized transport through single molecule magnets: $\mathrm{Mn}_{12}$ on $\mathrm{Au}(100) / \mathrm{Fe}(100) / \mathrm{MgO}(100)$
}

\author{
S. Voss ${ }^{\mathrm{a}, *}$, M. Fonin ${ }^{\mathrm{a}}$, F. Zinser ${ }^{\mathrm{a}, \mathrm{b}}$, M. Burgert ${ }^{c}$, U. Groth $^{c}$, U. Rüdiger ${ }^{\mathrm{a}}$ \\ "Department of Physics, University of Konstanz, 78457 Konstanz, Germany \\ Max Planck Institute for Solid State Research, 70569 Stuttgart, Germany \\ 'Department of Chemistry, University of Konstanz, 78457 Konstanz, Germany
}

\begin{abstract}
A B S T R A C T
The possibility to use the $\mathrm{Au}(100) / \mathrm{Fe}(100) / \mathrm{MgO}(100)$ system as a substrate for future spin-polarized transport measurements on $\mathrm{Mn}_{12}$ single molecule magnets has been investigated by means of scanning tunneling microscopy and X-ray photoelectron spectroscopy at room temperature. In particular, the stability of the iron layer during a wet chemical preparation of $\mathrm{Mn}_{12}$ monolayers was studied. The results demonstrate that $\mathrm{Mn}_{12}$ can be deposited on $\mathrm{Au}(100) / \mathrm{Fe}(100) / \mathrm{MgO}(100)$ while preserving the metallic nature of the ferromagnetic iron layer which is required as a possible source of spin-polarized electrons in future studies.
\end{abstract}

Keywords:

Single molecule magnets $\mathrm{Mn}_{12}$

\section{Introduction}

Stimulated by the discovery of the fascinating properties of $\mathrm{Mn}_{12}$ single molecule magnets (SMMs) [1,2], like quantum tunneling of magnetization or quantum phase interference effects [3a-d], different theoretical studies have predicted possibilities to address individual SMMs by means of a spin-polarized current $[4 a-c \mid$. In particular, the feasibility of switching the magnetization of a SMM coupled to ferromagnetic electrodes as well as possible signatures of the switching in electronic transport spectra were investigated theoretically. $\mathrm{Mn}_{12}$ may be particularly suited for such studies due to its relatively high blocking temperature $(\sim 3.5 \mathrm{~K})$ and the possibility of straightforward chemical modification of the ligand shell surrounding the magnetically active core [5a,b], which is required to deposit the molecules on a surface [6]. In principle, spin-polarized transport studies [7] on $\mathrm{Mn}_{12}$ can be performed in the near future as all ingredients required for the experiments are available [8]. In recent years, there has been significant progress in the field of spin-polarized scanning tunneling microscopy (STM) and spectroscopy (STS) [9a,b]. Furthermore, a large number of studies on the possibility to deposit $\mathrm{Mn}_{12}$ molecules on surfaces was performed $[6,10 \mathrm{a}-\mathrm{f}]$. The ultimate evidence for a deposition of intact $\mathrm{Mn}_{12}$ molecules is still lacking. While recent studies revealed the presence of homogeneous monolayers of molecules on $\mathrm{Au}(111)$ surfaces, no unambiguous evidence for the preservation of their magnetic properties or the usual oxidation states of the $\mathrm{Mn}$ ions within the $\mathrm{Mn}_{12}$ core $\left(\mathrm{Mn}^{\text {III }} / \mathrm{Mn}^{\text {IV }}\right)$ could be

* Corresponding author. Tel: +49 7531 883690; fax: +49 7531883789.

E-mail address; soenke.voss@uni-konstanz.de (S. Voss) obtained so far $[11 \mathrm{a}, \mathrm{b}]$. Nevertheless, there are indications that the molecules are not degraded during the deposition but due to the disruptive influence of the measurement techniques themselves [12a,b]. On the other hand, also non-destructive techniques revealed the lack of a magnetic hysteresis in $\mathrm{Mn}_{12}$ monolayers [10b,13] which might, however, be assigned to a reduced blocking temperature due to a molecule-surface interaction or an insufficient sensitivity of the techniques applied. Consequently, spinpolarized transport measurements at very low temperature are worth to be considered to figure out whether the magnetic properties of the $\mathrm{Mn}_{12}$ core are preserved after the deposition on a surface.

Here we report the preparation and investigation of $\mathrm{Mn}_{12}$ monolayers on $\mathrm{Au}(100) / \mathrm{Fe}(100) / \mathrm{MgO}(100)$ that may be used for future spin-polarized STM and STS measurements $[14 a-c]$. The results demonstrate that the metallic nature of the ferromagnetic iron layer can be preserved during the wet chemical preparation so that it might be used for spin injection in future experiments. Additionally, $\mathrm{Mn}_{12}$ was successfully grafted on $\mathrm{Au}(100)$ what demonstrates the general suitability of techniques previously developed for the deposition on $\mathrm{Au}\left(\begin{array}{lll}1 & 1 & 1\end{array}\right)$.

\section{Experimental}

$\left[\mathrm{Mn}_{12} \mathrm{O}_{12}\left(\mathrm{O}_{2} \mathrm{CC}_{6} \mathrm{H}_{4} \mathrm{~F}\right)_{16}(\mathrm{EtOH})_{4}\right]\left(\mathrm{Mn}_{12}-\mathrm{pfb}\right)$ and $4^{\prime}$-mercaptooctafluorobiphenyl-4-carboxylic acid (4-MOBCA) were synthesized as described elsewhere [10el. The $\mathrm{Au}(100) / \mathrm{Fe}(100) / \mathrm{MgO}(100)$ system was fabricated in an ultrahigh vacuum chamber (UHV; pressure below $10^{10} \mathrm{mbar}$ ) in four steps: (1) $\mathrm{MgO}$ was annealed at $1000 \mathrm{~K}$ for $1 \mathrm{~h}$ to remove contaminants and defects. (2) Fe was 


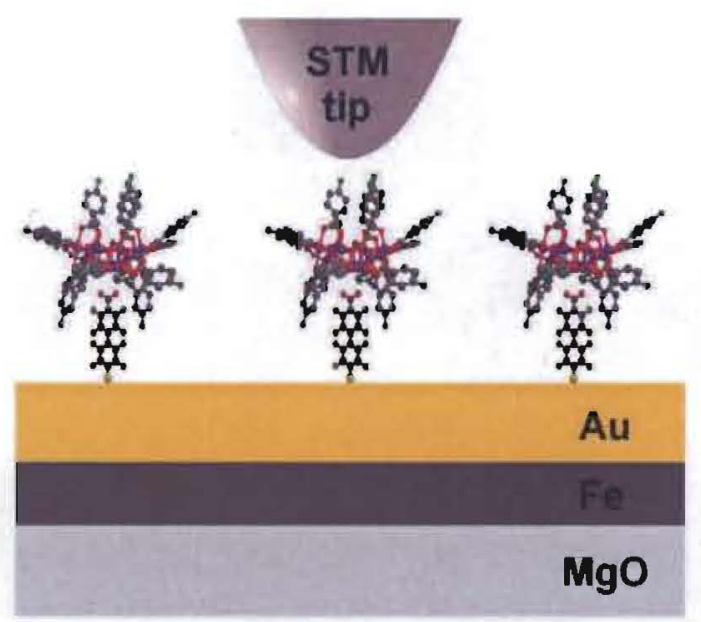

Fig. 1. Schematic representation of the STM investigation of $\mathrm{Mn}_{12}$-pfb deposited on $\mathrm{Au}(100) / \mathrm{Fe}(100) / \mathrm{MgO}(100)$ via ligand exchange reaction with 4-MOBCA.

evaporated onto $\mathrm{MgO}$ from an electron beam evaporator at room temperature at a rate of $1.5 \AA / \mathrm{min}$. (3) After the Fe deposition the sample was annealed at $870 \mathrm{~K}$ for $30 \mathrm{~min}$. (4) Finally. Au was evaporated from a thermal evaporator (effusion cell) at a rate of $6.5 \AA$ / min at a sample temperature of $600 \mathrm{~K}$. After the preparation and investigation of $\mathrm{Au}(100) / \mathrm{Fe}(100) / \mathrm{MgO}(100), \mathrm{Mn}_{12}$-pfb was deposited on the surface via ligand exchange reaction with 4-MOB$\mathrm{CA}$ as described elsewhere [10e]. A sketch of the sample configuration is shown in Fig. 1. STM, STS and X-ray photoelectron spectroscopy (XPS) measurements were performed in an Omicron Multiprobe UHV system at room temperature. For the STM/STS measurements, electrochemically etched tungsten tips, flash-annealed by electron bombardment were used. XPS spectra were obtained with $\mathrm{Al} K \alpha$ radiation $(h v=1486.6 \mathrm{eV}$ ) with the resolution of the EA 125 energy analyzer set to $0.65 \mathrm{eV}$.

\section{Results and discussion}

Fig. 2 shows two STM images obtained from $\mathrm{Fe}(100) / \mathrm{MgO}(100)$ (a; $16 \mathrm{~nm}$ thick iron layer) and from $\mathrm{Au}(100) / \mathrm{Fe}(100) / \mathrm{MgO}(100)$ (b; $20 \mathrm{~nm}$ thick gold layer). In Fig. 2a, Fe terraces along with monoatomic steps with perpendicular edges are visible which is in agreement with previous studies $[15 a, b]$. Fig. $2 b$ shows terraces and monoatomic steps of the $\mathrm{Au}(100)$ surface. The inset of Fig. $2 \mathrm{~b}$ shows the surface reconstruction of $\mathrm{Au}(100)$ which appears as a straight line pattern in contrast to the herringbone reconstruction of $\mathrm{Au}(1111)$. The surface morphology is in agreement with previous studies [16]. In the present study, the preparation parameters were optimized to fabricate surfaces with low roughness and sufficiently large Au terraces facilitating the addressing of $\mathrm{Mn}_{12}$ monolayers deposited on the surface by means of STM.

Fig. 3 shows an STM image obtained after deposition of $\mathrm{Mn}_{12}$ pfb on $\mathrm{Au}(100) / \mathrm{Fe}(100) / \mathrm{MgO}(100)$ via ligand exchange reaction with 4-MOBCA. A monolayer of clusters is visible which is in agreement with previous STM studies on $\mathrm{Mn}_{12}$ monolayers deposited on $\mathrm{Au}(111)$ single crystals $[10 \mathrm{e}, 12 \mathrm{a}]$. The shape of the subjacent terraces and steps can be estimated due to slight differences of the apparent height that are visible in the image. The individual molecules have been further investigated by means of scanning tunneling spectroscopy (STS; see inset of Fig. 3) which revealed the presence of a large conductance gap in agreement with previous studies [17]. In addition, XPS confirmed the presence of the Mn $2 p$ peaks also observed in previous works (see Fig. 4) [10e,12a]. The agreement with previous studies demonstrates that $\mathrm{Mn}_{12^{-}}$

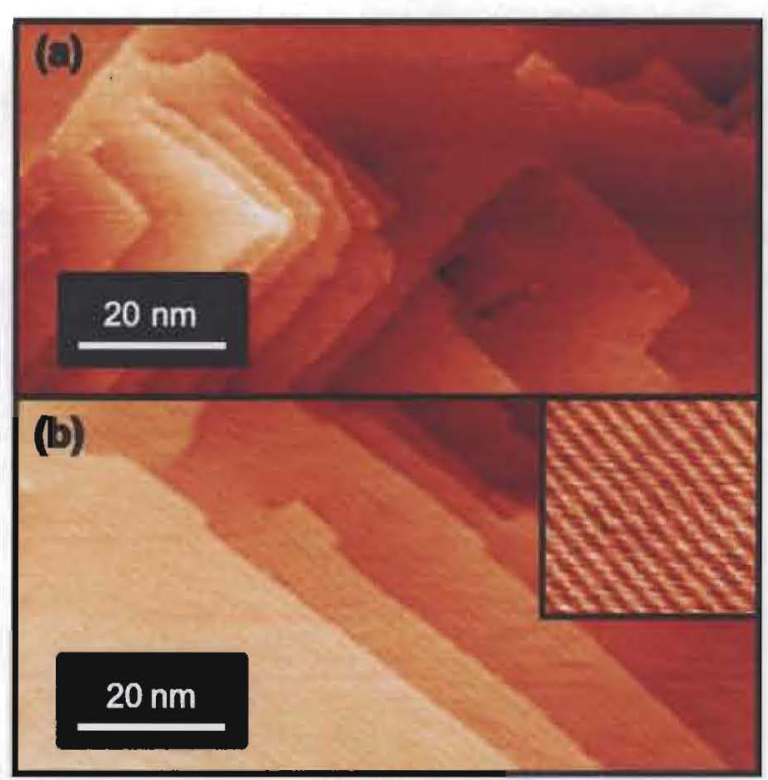

Fig. 2. STM images $\left(100 \times 50 \mathrm{~nm}^{2}\right)$ of (a) $\mathrm{Fe}(100) / \mathrm{MgO}(100)$ and (b) $\mathrm{Au}(100) /$ $\mathrm{Fe}(100) / \mathrm{MgO}(100)$. The inset of $(\mathrm{b})$ shows a $20 \times 20 \mathrm{~nm}^{2} \mathrm{STM}$ image of the surface reconstruction of $\mathrm{Au}(100)$.

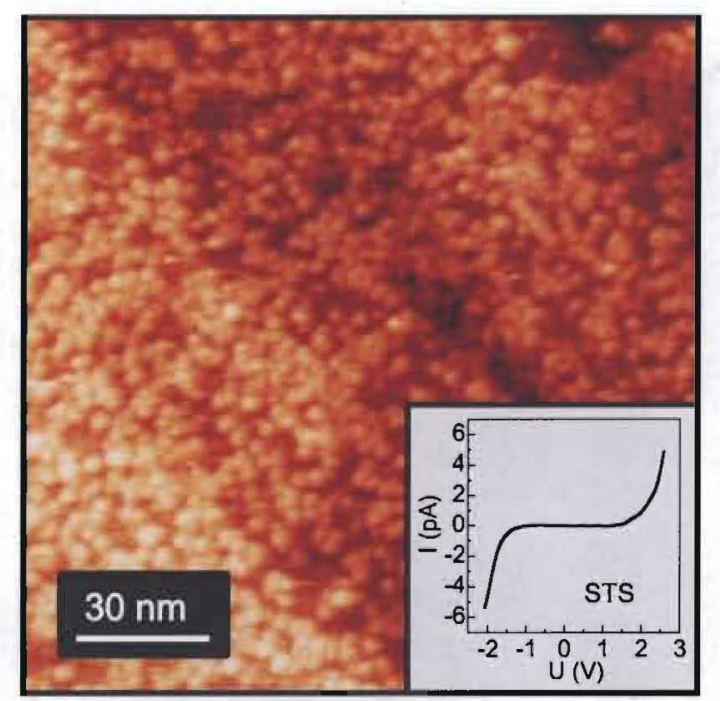

Fig. 3. STM image $\left(150 \times 150 \mathrm{~nm}^{2}\right)$ of $\mathrm{Mn}_{12}-\mathrm{pfb}$ molecules $\left(U_{1}=2.5 \mathrm{~V}_{;} i_{1}=8.6 \mathrm{pA}\right)$. The inset shows an STS spectrum of a single $\mathrm{Mn}_{12}-\mathrm{pfb}$ moleculc obtained at a set voltage of $2.7 \mathrm{~V}$ (set current $6.9 \mathrm{pA}$ )

pfb was successfully deposited on $\mathrm{Au}(100) / \mathrm{Fe}(100) / \mathrm{MgO}(100)$. Furthermore, the results demonstrate that details of the gold surface morphology, like different surface reconstructions or terrace shapes in the case of $\mathrm{Au}(100)$ and $\mathrm{Au}(111)$ do not significantly influence the arrangement of the $\mathrm{Mn}_{12}$ molecules. This observation is in agreement with a previous study which suggested a statistical arrangement of $\mathrm{Mn}_{12}$ on 4-MOBCA/Au [10e].

To investigate a possible influence of the wet chemical deposition of $\mathrm{Mn}_{12}$ on the properties of the Au-covered iron layer, XPS measurements were performed in order to detect a possible oxidation of the iron. Fig. $5 a$ shows a Fe $2 p$ spectrum obtained from $\mathrm{Fe}(100) / \mathrm{MgO}(100)$. The peak positions (Fe $2 p_{1 / 2}: 719.9 \mathrm{eV}, \mathrm{Fe}$ 


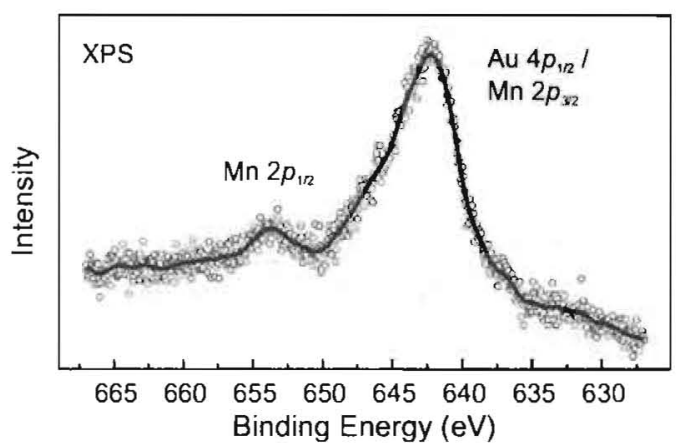

Fig. 4. XPS $M n 2 p / A u 4 p_{1 / 2}$ spectrun obtamed after deposition of $M n_{12}$-pfb on $\mathrm{Au}(100) / \mathrm{Fe}(100) / \mathrm{MgO}(100)$.

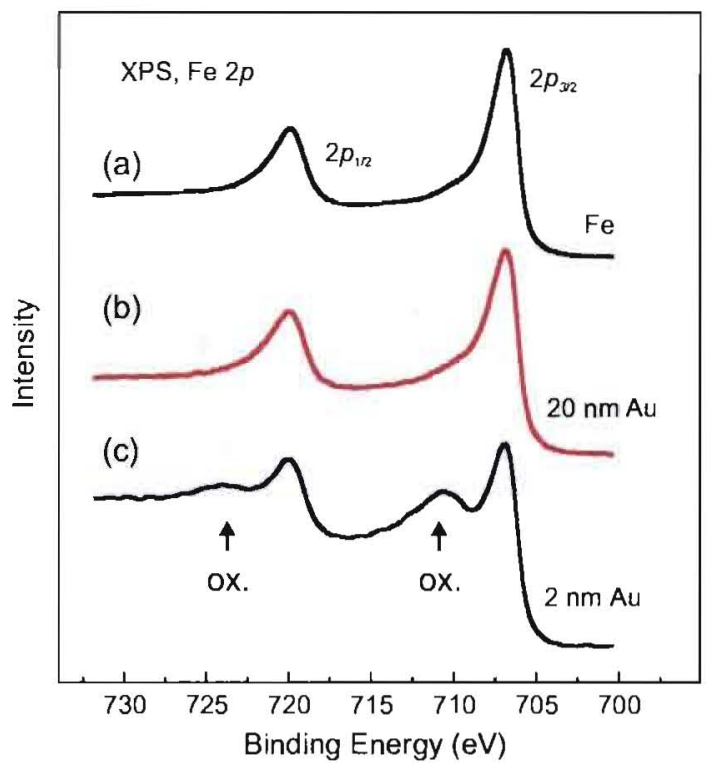

Fig. 5. XPS Fe $2 p$ spectra of (a) $\mathrm{Fe}(100) / \mathrm{MgO}(100)$ (after in situ Fe evaporation), (b) $\mathrm{Mn}_{12}$-pfb on $\mathrm{Au}(100)(20 \mathrm{~nm}] / \mathrm{Fe}(100) / \mathrm{MgO}(100)$ after removal of $\mathrm{Mn}_{12}$, 4-MOBCA and $\mathrm{Au}$ via sputtering. (c) $\mathrm{Mn}_{12}$-pfb on $\left.\mathrm{Au}(100) / 2 \mathrm{~nm}\right] / \mathrm{Fe}(100) / \mathrm{MgO}(100)$ after removal of $\mathrm{Mn}_{12}, 4-\mathrm{MOBCA}$, and $\mathrm{Au}$ via sputtering.

$2 p_{3 / 2}: 706.8 \mathrm{eV}$ ) as well as the shape of the spectrum are consistent with metallic iron [18]. This measurement was performed immediately after the deposition of $\mathrm{Fe}$ on $\mathrm{MgO}$. It is well known that removing the unprotected iron layer from the UHV would result in an oxidation. Hence, sensitive samples are usually covered with protection layers like gold thin films prior to sample transfers or further processing. Nevertheless, it is important to carefully investigate the $\mathrm{Mn}_{12} / \mathrm{Au}(100) / \mathrm{Fe}(100) / \mathrm{MgO}(100)$ system since the adopted preparation steps (immersion in solvents [19], possibly corrosive 4-MOBCA etc.) are significantly different from an ordinary sample transfer. To study a possible oxidation of the iron layer during the preparation ex situ, the $\mathrm{Mn}_{12} / 4-\mathrm{MOBCA} / \mathrm{Au}(100)$ layers had to be removed from the sample because the information depth of XPS is limited to a few $\mathrm{nm}$ [20]. To this end, the sample was continually sputtered with $\mathrm{Ar}^{+}$ions at $800 \mathrm{eV}$ for $10 \mathrm{~min}$ in each step. After each sputtering cycle, an XPS spectrum was recorded. Due to the XPS information depth of a few $\mathrm{nm}$ the transition from a pure Au to a mixed $\mathrm{Au} / \mathrm{Fe}$ signal could be easily identified and the sputtering was terminated at this time to avoid an accidental removal of a possibly oxidized iron layer. Subsequently, a XPS Fe $2 p$ spectrum was recorded. Fig. 5b shows the spectrum obtained from the sample previously covered with $\mathrm{Mn}_{12}$. The spectrum coincides with those of metallic iron and thus provides evidence that the iron layer was not oxidized. In the next step, a control experiment was performed with an only $2 \mathrm{~nm}$ thick Au layer while all different parameters and preparation steps were identical to those of the previous sample. Fig. $5 c$ shows an Fe $2 p$ spectrum that reveals the occurrence of additional Fe $2 p$ peaks after the exposure to ambient conditions. The comparison of the position of the additional Fe $2 p_{3 / 2}$ peak. (710.5 eV) with previous studies indicates a partial oxidation of the iron layer [18].

The comparison of the XPS spectra demonstrates that the iron layer underneath the $20 \mathrm{~nm}$ Au layer is not oxidized during the wet chemical deposition of $\mathrm{Mn}_{12}$ while in the case of a thin layer an oxidation cannot be ruled out. This observation suggests a trade-off between oxidation protection and spin polarization. Although the spin diffusion length in Au can be significantly larger than $20 \mathrm{~nm}[21]$, a thin buffer layer may be preferable to achieve a sufficient spin injection.

In conclusion, a possibility to fabricate samples for future spin-polarized transport studies on $\mathrm{Mn}_{12}$ single molecule magnets was investigated. The results demonstrate that $\mathrm{Mn}_{12}$ molecules can be deposited on $\mathrm{Au}(100) / \mathrm{Fe}(100) / \mathrm{MgO}(100)$ layer systems by means of wet chemical deposition methods without altering the metallic nature of the ferromagnetic iron which is required as a source for spin-polarized electrons. The insights will contribute to future transport studies on $\mathrm{Mn}_{12}$ and possibly different single molecule magnets.

\section{Acknowledgement}

This work was supported by the Deutsche Forschungsgemeinschaft (DFG) via the Collaborative Research Center (SFB) 767. project $\mathrm{C} 5$.

\section{References}

[1] D. Gatteschi, R. Sessoli, Angew. Chem., Int. Ed. 42 (2003) 268.

[2] G. Christou, D. Gatteschi, D.N. Hendrickson, R. Sessoli, MRS Bull. 25 (2000) 66

|3| (a) J.R. Friedman, M.P. Sarachik, J. Tejada, R. Ziolo, Phys. Rev. Lett. 76 (1996) 3830;

(b) L. Thomas, F. Lionti, R. Ballou, D. Gatteschi, R. Sessoli, B. Barbara, Nature 383 (1996) 145;

(c) E. del Barco, A.D. Kent. S. Hill, J.M. North, N.S. Dalal, E.M. Rumberger, D.N. Hendrickson, N. Chakov, G. Christou, J. Low Temp. Phys. 140 (2005) 119 ;

(d) W. Wernsdorfer, N.E. Chakov, G. Christou, Phys. Rev. Lett. 95 (2005) 037203.

[4] (a) M. Misiorny. J. Barnas, Phys. Rev. B 75 (2007) 134425:

(b) F. Elste, C. Timm, Phys. Rev. B 73 (2006) 235305;

(c) M. Misiorny, J. Barnas, Phys. Rev. B 76 (2007) 054448.

[5] (a) P. Artus, C. Boskovic, J. Yoo, W.E. Streib, L.-C. Brunel, D.N. Hendrickson, G. Christou, Inorg. Chem. 40 (2001) 4199;

(b) R. Sessoli, H.-L. Tsai, A.R. Schake, S. Wang, J.B. Vincent, K. Folting, D. Gatteschi, G. Christou, D.N. Hendrickson, J. Am. Chem. Soc. 115 (1993) 1804.

[6] A. Cornia, A.C. Fabretti, M. Pacchioni, L. Zobbi, D. Bonacchi. A. Caneschi, D. Gatteschi, R. Biagi, U. del Pennino, V. de Renzi, L. Gurevich, H.S.J. van der Zant. Angew. Chem. 115 (2003) 1683.

[7] S.A. Wolf, D.D. Awschalom, R.A. Buhrman, J.M. Daughton, S. von Molnar, M.L Roukes, A.Y. Chtchelkanova, D.M. Treger, Science 294 (2001) 1488.

[8] L. Bogani, W. Wernsdorfer, Nat. Mater. 7 (2008) 179.

[9] (a) R. Wiesendanger, H.-J. Güntherodt, G. Güntherodt, R.J. Gambino, R. Ruf, Phys. Rev. Lett. 65 (1990) 247;

(b) S. Krause, L. Berbil-Bautista, G. Herzog. M. Bode, R. Wiesendanger, Science 317 (2007) 1537

[10] (a) L. Zobbi, M. Mannini, M. Pacchioni, G. Chastanet, D. Bonacchi, C. Zanardi, R. Biagi, U. del Pennino, D. Gatteschi, A. Cornia, R. Sessoli, Chem. Commun. (2005) 1640 ;

(b) A. Naitabdi, J.-P. Bucher, P. Gerbier, P. Rabu, M. Drillon, Adv. Mater. 17 (2005) 1612:

(c) M. Cavallini, M. Facchini, C. Albonetti, F. Biscarini, Phys. Chem. Chem. Phys, 10 (2008) 784 ;

(d) J. Goinez-Segura, J. Veciana, D. Ruiz-Molina, Chem. Commun. (2007) 3699 (e) M. Burgert, S. Voss, S. Herr, M. Fonin, U. Groth, U. Rüdiger, J. Am. Chem. Soc. 129 (2007) 14362; 
(f) S. Voss, O. Zander, M. Fonin, U. Rüdiger, M. Burgert, U. Groth, Phys. Rev, B 78 (2008) 155403.

[11] (a) M. Mannini, P. Sainctavit, R. Sessoli, C.C. dit Moulin, F. Pineider, M.-A. Arrio, A. Cornia, D. Gatteschi, Chem. Eur. J. 14 (2008) 7530;

(b) S. Voss, M. Fonin, U. Rüdiger, M. Burgert, U. Groth, Phys. Rev. B 75 (2007) 045102.

[12] (a) S. Voss, M. Burgert, M. Fonin, U. Groth, U. Rüdiger, Dalton Trans. (2008) 499:

(b) S. Voss, M. Fonin, L. Burova, M. Burgert, Y.S. Dedkov, A.B. Preobrajenski, E. Goering, U. Groth, A.R. Kaul, U. Ruediger, Appl. Phys. A. in press, doi: 10.1007/ s00339-008-4911-6.

[13] L. Bogani, L. Cavigli, M. Gurioli, R.L. Novak, M. Mannini, A. Caneschi, F. Pineider. R. Sessoli, M. Clemente-Leon, E. Coronado, A. Cornia, D. Gatteschi, Adv. Mater. 19 (2007) 3906.

[14] (a) J.A. Stroscio, D.T. Pierce, A. Davies, R.J. Celotta, M. Weinert, Phys. Rev. Lett. 75 (1995) 2960; (b) M. Getzlaff, J. Bansmann, G. Schönhense, Fresenius J. Anal. Chem. 353 (1995) 748;

(c) T. Ohkochi, K. Mibu, N. Hosoito, J. Phys. Soc. Jpn. 75 (2006) 104707.

[15] (a) A. Subagyo. H. Oka, G. Eilers, K. Sueoka, K. Mukasa, Jpn. J. Appl. Phys. 39 (2000) 3777 ;

(b) K. Thürmer, R. Koch, M. Weber, K.H. Rieder, Phys. Rev. Lett. 75 (1995) 1767

[16] N. Spiridis, J. Korecki, Appl. Surf. Sci. 141 (1999) 313.

[17] S. Voss, M. Fonin. U. Rüdiger, M. Burgert, U. Groth. Appl. Phys. Lett. 90 (2007) 133104.

[18] V. Di Castro, S. Ciampi, Surf. Sci. 331-333 (1995) 294.

[19] W.R.T. Barden, S. Singh, P. Kruse, Langmuir 24 (2008) 2452

[20] M.P. Seah, W.A. Dench. Surf. Interface Anal. 1 (1979) 2

[21] J.-H. Ku, J. Chang. H. Kim, J. Eom, Appl. Phys, Lett. 88 (2006) 172510. 